\title{
A relação educação-folclore no governo de Juscelino Kubitschek
}

Luís Fernando Gotarde

Pedagogo e ex-bolsista de Iniciação Científica pelo PIBIC/CNPQ

\section{Resumo}

Para o fortalecimento e difusão do nacional-desenvolvimentismo dos anos 50, no Brasil, participaram diversos agentes, entre estes o folclore, que, ao se articular à educação e à imprensa escrita, foi elemento ideológico integrante na construção de uma identidade nacional. Este trabalho tem por objetivo abordar teoricamente a relação educação-folclore, identificá-la e descrevê-la a partir da análise do que foi veiculado pela imprensa escrita acerca do tema e pela legislação pertinente do período.

Palavras-chave: Educação; Folclore; Nacional-Desenvolvimentismo.

\begin{abstract}
For the strengthening and difusion of the 50's natural development, many agents have participated, among them the folklore, that, when articulated to Education and written press, was an ideological element integrated in the construction of a national identity. This paperwork has the objective of theorically cover the relation between Education-Folklore, identify it and describe it from the analysis of what was displayed by the written press about the theme and by the applicable legislation of the period.
\end{abstract}

Keywords: Education; Folklore; National Development. 


\section{Introdução}

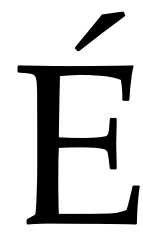

importante esclarecer que este artigo é fruto de uma pesquisa vinculada ao Programa Institucional de Bolsas de Iniciação Científica - PIBIC -, e financiada pelo Conselho Nacional de Desenvolvimento Científico e Tecnológico - CNPq -, quota Julho de 2008/Julho de 2009. Neste texto procurou-se apenas apresentar de forma sucinta o que foi realizado na referida pesquisa, além de focar alguns pontos relevantes relacionados aos fundamentos teóricos, metodologia de pesquisa, análise de dados e conclusões. O texto integral referente à pesquisa foi publicado, em 2009, em forma de Trabalho de Conclusão de Curso, intitulado: A relação entre educação e folclore abordada na imprensa escrita - em Campinas - durante o Governo de Juscelino Kubitschek (19561961).

Após os comentários iniciais, pode-se, portanto, iniciar a discussão.

No Governo de Juscelino Kubitschek, assim como em todo o decorrer dos anos 50 e 60, o Brasil viveu um momento em que o populismo, a doutrina nacionalista e a idéia de desenvolvimentismo convergiam no sentido de concretizar projetos de nação. Projetos, esses, de investimento na indústria e na modernização da agricultura para o crescimento econômico e principalmente industrial do país. Contribuindo para a difusão e o fortalecimento do ideário nacional-desenvolvimentista no referido contexto, participaram diversos agentes, entre eles o folclore, que, ao se articular à educação de um modo geral, ao ensino público e à imprensa escrita, foi elemento ideológico integrante na construção de uma identidade nacional brasileira. Ao se indagar sobre a relação entre educação e folclore dentro do período correspondente ao Governo de JK, este trabalho teve por objetivo abordar teoricamente essa relação, identificá-la e descrevê-la a partir da análise do que foi veiculado pela imprensa escrita acerca das manifestações folclóricas e pela legislação pertinente do período.

A partir dos fragmentos de jornal e a produção científica de Dermeval Saviani, Florestan Fernandes, Antônio Gramsci, entre outros 
autores, pode-se afirmar que existiu, sim, em Juscelino Kubitschek um plano de nação, parcialmente concretizado, que contou com a colaboração do folclore como elemento cultural na construção de uma suposta identidade coletiva nacional, ainda que múltipla.

Para se refletir acerca da relação entre educação e folclore abordada na imprensa escrita, em qualquer contexto histórico, é preciso definir minimamente: $(a)$ o que é educação; $(b)$ qual o contexto social focado, em seus aspectos materiais, espirituais e ideológicos; $(c)$ o que é folclore e qual o seu significado, na visão de mundo dos atores desse contexto e na visão dos autores que dão sustentação teórica à pesquisa; $(d)$ qual a relação entre folclore e educação, de que maneira e em que medida ela ocorreu dentro desse contexto; (e) por que o pesquisador escolheu a investigação da imprensa daquela época como caminho para se chegar aos objetivos da pesquisa; $(f)$ qual o grau de imparcialidade dos métodos e análises adotados nesta pesquisa; $(g)$ qual a importância da reflexão acerca de tudo isso e o que se pode concluir a partir dela.

\section{O objeto de pesquisa: a relação educação-folclore}

Conceituar folclore e caracterizar com exatidão fato folclórico não são tarefas fáceis. Não é por acaso que há muito existe um debate epistemológico entre folcloristas e cientistas sociais; ambas as áreas visando delimitar seu campo de trabalho e determinar a natureza do objeto de estudo folclore. Fernandes (1989) trata da existência e da natureza dessas dificuldades na obra $O$ folclore em questão, mais especificamente no Capítulo 2: Objeto e campo do folclore, quando mostra a possibilidade de se estudar e pesquisar o folclore a partir de duas perspectivas, que se abrem num leque de várias possibilidades. A primeira: o folclore sob um olhar nãocientífico; a segunda: o folclore sob o olhar das ciências sociais, logo, científico. Nos próximos parágrafos, elucidar-se-ão as diferenças entre estas duas perspectivas. 
A primeira perspectiva, portanto, é a que enxerga o estudo e a pesquisa do folclore a partir de métodos despreocupados com o olhar científico. No caso dessa visão não-científica, permitir-se-ia, por exemplo, considerar o folclore como um conjunto de saberes de um determinado estrato social, ou como processo de criação e/ou renovação de valores estéticos. Neste caso, evidenciaria-se a importância do valor estético do folclore.

A segunda perspectiva trazida por Fernandes (1989) refere-se ao olhar das ciências sociais sobre o folclore, que enfoca outros aspectos, diversos dos estéticos, como a suposta conexão entre fatos folclóricos e o comportamento humano e as mudanças que se operam no campo da cultura e da organização social. Nas palavras do autor:

[...] a análise feita por disciplinas como a psicologia, a psicologia social, a etnologia e a sociologia só é suscetível de esgotar as questões que devem ser explicadas em termos da abstração de conexões do folclore com o comportamento humano, a dinâmica da cultura e a organização social que possam ser submetidas a alguma espécie de tratamento indutivo amplificador (FERNANDES, 1989, p.23).

Assim, essas disciplinas têm como campo de estudo e pesquisa a relação entre folclore e sociedade. Através de um método indutivo, procurase correlacionar as práticas presentes nestes dois campos, deixando de enfatizar outras questões, como as estéticas. Dito por Fernandes:

[...] as ciências sociais deixam de lado, de modo inevitável, outras questões, concernentes a aspectos do folclore que não podem ser reduzidos à explanação nomotética ou generalizadora. Ora, entre tais questões se incluem temas essenciais, de que dependem a própria explicação da natureza do folclore como forma de saber e como processo intelectual de criação ou de renovação de valores estéticos (FERNANDES, 1989, p.23-24).

Outro autor que trata do assunto é Antonio Gramsci, para quem se pode colocar a mesma pergunta o que é folclore?

Após a leitura do sexto volume de Cadernos do Cárcere, onde se encontra grande parte dos escritos de Gramsci sobre folclore, procurou-se interpretar a partir de cada fragmento, a concepção do autor sobre o tema. 
Assim, de fragmento em fragmento foi-se construindo o significado de folclore. Para o autor:

seria preciso estudar o folclore [...] como 'concepção do mundo e da vida', em grande medida implícita, de determinados estratos (determinados no tempo e no espaço) da sociedade, em contraposição (também esta, na maioria dos casos, implícita, mecânica, objetiva) às concepções do mundo 'oficiais' (ou, em sentido mais amplo, das partes cultas das sociedades historicamente determinadas) que se sucederam no desenvolvimento histórico. (Daí a estreita relação entre folclore e 'senso comum', que é o folclore filosófico) (GRAMSCI, 2002, p.133-136).

Gramsci adota, ainda, em vários fragmentos de Cadernos do Cárcere, os termos "oficial" ou "dos intelectuais" ou "hegemônica", em oposição a "do povo". Por exemplo: "religião do povo" e "religião do intelectuais" (ibidem, p.134), "moral do povo" e "moral oficial" (ibidem, p.135). Desta maneira, é possível conceber que o autor considera, sim, como elemento integrante do folclore a concepção do mundo e da vida "de determinados estratos sociais", que são distintas em relação às "concepções oficiais"(ibidem, p.133).

A partir da leitura do fragmento anterior, é importante, ainda, esclarecer: quem compõe esses "determinados estratos sociais"? O que são “concepções oficiais"? E o que significa dizer que "a concepção do mundo e da vida de determinados estratos sociais é distinta das concepções oficiais”?

A resposta à primeira pergunta encontra-se na continuação do fragmento:

Concepção do mundo [de determinados estratos sociais] não só elaborada e assistemática - já que o povo (isto é, o conjunto das classes subalternas e instrumentais de toda forma de sociedade que existiu até agora) não pode, por definição, ter concepções elaboradas, sistemáticas e politicamente organizadas e centralizadas em seu (ainda que contraditório) desenvolvimento -, como também múltipla (ibidem, p.133-136).

Esses estratos sociais aos quais se refere o autor é o conjunto das classes subalternas e instrumentais de toda forma de sociedade que existiu até os dias atuais. 
Em resposta a segunda e terceira perguntas, citar-se-á Luciano Gruppi.

Gruppi, em O Conceito de Hegemonia em Gramsci, coloca que, para Gramsci, todo homem é filósofo pelo simples fato de ser homem, por possuir linguagem, por participar do senso comum ou por aderir a uma religião, ainda que na forma mais simples e popular. Gramsci, nesse enunciado, referir-se-ia, segundo Gruppi, à vida cultural das classes subalternas, dos trabalhadores, dos camponeses. Assim, todo homem, pelo simples fato de que fala, tem uma concepção do mundo, ainda que não consciente, ainda que acrítica, já que a linguagem é sempre, embrionariamente, uma forma de concepção de mundo (GRUPPI, 1978, p.66-67).

A consciência acrítica do homem é, portanto, o resultado da relação deste com o ambiente, em que estão inclusas as ideologias presentes na sociedade (contemporânea ou não) em sua totalidade, possivelmente fragmentadas em ideologias advindas de estratificações sociais, ou ainda ideologias derivadas de culturas diversas, ou seja: elementos que permaneceram no saber popular, e que compõem esta consciência subordinada, espontânea, não criticamente unificada e não consciente do que é.

Entretanto, existe, segundo Gramsci, concepções de mundo dominantes, às quais o povo, a priori, é ou está sujeito. Concepções, essas, que se traduzem em ideologias correspondentes aos interesses e à função histórica das classes dominantes, em detrimento da função histórica e dos interesses das classes subalternas.

Vários são os canais através dos quais essas ideologias (das classes dominantes) podem ser difundidas. Alguns são: a escola, a religião, o serviço militar, o cinema, os jornais, os episódios de cultura local e as manifestações do folclore (ibidem, p.68). Este, além de sinônimo de saberes populares, compreende um conjunto (Gramsci utiliza o termo “aglomerado") de saberes, a priori populares ou não, que com o decorrer do tempo foram se acumulando em forma de cultura popular. 
Quando o autor coloca folclore como "concepção do mundo e da vida", reconhece neste seu caráter múltiplo, já que muitos saberes poderiam ser "inseridos" ao que Gramsci chama de folclore, inclusive os saberes científicos e filosóficos que se concentram, geralmente, no circuito das classes dominantes. Nas palavras do autor:

seria preciso estudar o folclore [...] como 'concepção do mundo e da vida' [...]. Concepção do mundo [de determinados estratos sociais] não só elaborada e assistemática [...], como também múltipla. Múltipla não apenas no sentido de algo diversificado e justaposto, mas também no sentido de algo estratificado, do mais grosseiro ao menos grosseiro, se é que não se deve até mesmo falar de um aglomerado indigesto de fragmentos de todas as concepções do mundo e da vida que se sucederam na história, da maioria das quais, aliás, somente no folclore é que podem ser encontrados os documentos mutilados e contaminados que sobreviveram (GRAMSCI, 2002, p.133-136).

Como foi dito, os saberes científicos e filosóficos também compõem o saber popular, colaborando para a formação do folclore. Entretanto, ao ser incorporado pelas massas, os saberes que em sua origem correspondiam à ciência e à filosofia, sofrem modificações:

Também o pensamento e a ciência moderna fornecem continuamente novos elementos ao 'folclore moderno', na medida em que certas noções científicas e certas opiniões, subtraídas de seu contexto e mais ou menos desfiguradas, caem continuamente no domínio popular e são 'inseridas' no mosaico da tradição (ibidem, p.133136).

$\mathrm{Na}$ tentativa de se subtrair um conceito de folclore a partir das discussões até aqui realizadas, notou-se que existe um ponto nebuloso, conceitualmente, quando se diz que o folclore se contrapõe à ideologia dominante, pois: admitindo que a classe ou classes dominantes têm no folclore justamente um espaço de inserção de sua própria ideologia na sociedade no intento de estabelecer sua hegemonia, pergunta-se: como pode um saber imposto por uma classe, no caso a dominante, ser contrário aos interesses desta mesma classe? 
Em meio a esta contradição, admitiu-se a possibilidade da existência de um terceiro caminho, ao considerar, então, que fazem parte do folclore saberes e manifestações que podem ou não se contrapor aos interesses das classes dominantes.

Assim, acredita-se ser possível elencar elementos que fazem parte do que Gramsci considera como folclore, ao invés de simplesmente formular um conceito engessado e resolvido em seu significado. O conceito de folclore a que se chegou inicialmente, baseando-se nos escritos de Gramsci, foi: todo o saber ou manifestação popular, dotados de múltiplas origens localizadas tanto na contemporaneidade como no passado -, nos quais estão presentes as concepções do mundo e da vida desse estrato social, e que podem ou não se contrapor aos interesses das classes dominantes.

\section{A relação educação-folclore no Governo de Juscelino Kubitschek}

É evidente que aliados à dominação racional legal exercida pelo Estado e pelas elites sobre a sociedade estão os mediadores superestruturais de criação e vulgarização de ideologias, que colaboram para a concretização de um projeto de nação favorável àquelas.

Anita Helena Schlesener, em um artigo, coloca que:

O Estado, ao exercer a sua função efetiva de implementar um projeto econômico e político, também realiza a sua função educativa de adequar os indivíduos às exigências da produção e às condições sociais de uma época e de uma sociedade, ou seja, a política efetiva-se pela relação com a cultura e toda ação que vise concretizar um projeto político precisa considerar a questão da formação do homem (2009).

No caso brasileiro, especificamente no Governo de Juscelino Kubitschek, os rumos da educação eram dados pela pedagogia moderna, cujas bases ideológicas coadunavam com os interesses do progresso, do desenvolvimento, do avanço material da civilização.

A ideologia do nacional-desenvolvimentismo, no Brasil, contou com o apoio do Instituto Superior de Estudos Brasileiros (ISEB), criado em 
1955, no Governo de Café Filho, e que, na gestão de JK, colaborou profundamente para o fortalecimento dessa ideologia.

O nacionalismo, como foi dito, compreende uma doutrina ou filosofia política que legitima a devoção e a lealdade dos indivíduos à nação, visando o bem estar social através da coesão dos interesses destes indivíduos em prol do bem comum e a construção de uma identidade coletiva nacional (ENCINA e ONRAITA, 2004).

A partir disso, compreende-se que na implementação de um projeto de nação é necessário que o Governo e as elites lancem mão de meios para adequar materialmente e ideologicamente as classes subalternas aos seus interesses e às exigências de produção material. Essa adequação se dá tanto em caráter educacional como cultural, e certamente decorre da formação, atribuindo à educação, assim como ao folclore, o papel de elemento de conformação e/ou reprodução. Dessa maneira, é possível estabelecer, no mínimo, duas relações entre educação e folclore.

A primeira relação entre educação e folclore, nesse contexto, é que o folclore, em si, é educativo, porque carrega e reproduz a cultura popular de uma geração à outra.

A segunda relação existe quando da presença do folclore na educação escolar como prática curricular real nas instituições oficiais ou privadas. Essa presença, no caso brasileiro, foi oficializada em 1961, com a emissão do Decreto $\mathrm{n}^{\circ}$ 51.215, que estabelece a obrigatoriedade do ensino do folclore nos estabelecimentos públicos e privados de ensino regular, e em 17 de Agosto de 1965, quando o então Presidente da República Castello Branco, através do Decreto $\mathrm{n}^{\circ} 56.747$, estabeleceu que fosse celebrado anualmente, a 22 de Agosto, em todo o território nacional, o "Dia do Folclore", incumbindo a Campanha Nacional de Defesa do Folclore e a Comissão Nacional do Folclore, juntamente com as comissões regionais, de comemorar o Dia do Folclore e estimular, nos estabelecimentos de curso primário, médio e superior, as celebrações que realçassem a importância do folclore na formação cultural do país. Dessa maneira, o folclore vincula-se à educação em seu bojo: as instituições escolares oficiais. 


\section{Os canais de instauração e manutenção da hegemonia:} a escola, o folclore e a imprensa

O que é hegemonia?

Gruppi (1978) resgata a origem do significado do termo hegemonia, que deriva do grego eghestai, que significa conduzir, ser guia, ser líder; ou também do verbo eghemoneuo, que significa ser guia, preceder, conduzir, e do qual deriva estar à frente, comandar, ser o senhor.

Para Gramsci, hegemonia é:

capacidade de unificar através da ideologia e conservar unido um bloco social que não é homogêneo, mas sim marcado por profundas contradições de classe. Uma classe é hegemônica, dirigente e dominante, até o momento em que - através de sua ação política, ideológica e cultural - consegue manter articulado um grupo de forças heterogêneas, e consegue impedir que o contraste existente entre tais forças exploda, provocando assim uma crise na ideologia dominante, que leve à recusa de tal ideologia, fato que irá coincidir com a crise política das forças no poder (GRUPPI, 1978, p.70).

E como manter a hegemonia sobre as classes subalternas?

Gruppi (1978, p.68) coloca que a relação infra-estrutura e superestrutura é estabelecida através de mediadores que atuam como meio de criação e difusão da ideologia dominante, com o intuito de manter seu poder sobre as classes subalternas. Esses mediadores superestruturais (ou canais) podem ser, entre outros, a escola, a religião, o serviço militar, o cinema, os jornais, os episódios de cultura local e as manifestações do folclore.

Este trabalho focalizou, diretamente, o estudo/pesquisa de determinados mediadores: a educação e o folclore, e indiretamente a imprensa. 


\section{Metodologia de coleta e análise de dados e alguns dos possíveis vieses}

Este item Metodologia de coleta e análise de dados e alguns dos possíveis vieses busca elucidar os critérios utilizados na seleção das fontes e alguns dos possíveis vieses decorrentes de tais seleções, e a metodologia utilizada na coleta e análise de dados.

A metodologia de coleta de dados utilizada foi a busca - nos exemplares de jornais - de matérias, artigos etc. que se enquadram em uma ou mais das seguintes categorias:

$>$ DE - manifestações folclóricas ou conteúdo em alusão a estas, ocorridas dentro do espaço escolar oficial;

FVE - manifestações folclóricas ou conteúdo em alusão a estas, ocorridas fora do espaço escolar oficial, mas vinculadas a ele; e

FE - manifestações folclóricas ou conteúdo em alusão a estas, ocorridas fora do espaço escolar oficial.

Partindo-se do pressuposto de que o folclore está presente dentro e fora da instituição escolar, a discriminação em três categorias do conteúdo encontrado nos fragmentos dos jornais satisfazem um objetivo específico de constatar o grau de interesse do Governo da época em investir na difusão do folclore na sociedade, sob a premissa de que o ensino público pode ser considerado um canal muito eficaz para o referido propósito.

\section{O jornal}

A justificativa para a opção de coletar dados nos jornais reside no fato de que o meio de comunicação de massa jornal compreende, em si, um dos canais de circulação e divulgação dos ideários de diferentes grupos e segmentos sociais. A análise, portanto, do conteúdo vinculado nesse canal possibilitaria ao pesquisador a obtenção de um retrato, ainda que parcial, desses possíveis ideários.

Quando se busca identificar nos meios de comunicação de massa a presença de determinadas ideologias, ou "visões de mundo" (LOWŸ, 2003), é 
muito provável que se encontre um aglomerado dessas, difusas em linguagem escrita, falada ou iconográfica.

No caso do jornal, identificar-se-ão, evidentemente, preferências a determinada crença ou religião em detrimento de outras, ou opiniões e posicionamentos parciais em relação a diversos assuntos, derivadas, obviamente, dos interesses a que veio o jornal. Por um lado, trata-se de um viés inevitável presente em pesquisa em jornais e outros meios de comunicação, por outro, é justamente essa imparcialidade, presente nestes canais comunicativos, que os caracteriza como mediadores superestruturais, reforçando sua função como tal. Assim, o jornal sendo um instrumento ideologizante, carrega, sim, em si, conteúdos relacionados aos interesses daqueles que o conceberam, não sendo dotado de neutralidade. A escolha de um determinado jornal em detrimento de outro acarreta também, indireta e inevitavelmente, uma seleção de conteúdo, o que não invalida a pesquisa, mas resulta em maior ou menor parcialidade na obtenção dos resultados.

Em outro caso específico, o da educação escolar, é possível submetermos à análise outras fontes de informações, como registros escritos de conteúdos transmitidos aos alunos, livros didáticos utilizados etc, o que possibilitaria ao pesquisador, novamente, identificar a presença de valores e/ou ideários no currículo de determinada escola ou sistema educacional. Dessa maneira, o conteúdo realmente trabalhado no interior do espaço escolar seria um ponto de intersecção entre: o que o Governo pretendia incorporar à educação de massa através da escola, e as visões de mundo dos atores envolvidos no processo educativo. A opção pelos jornais se deu sem desconsiderar a importância de se investigar documentos históricos relativos ao cotidiano escolar da época.

\section{Análise dos dados}

Foram traçados dois objetivos diante da análise dos fragmentos: (i) identificar no conteúdo dos fragmentos coletados a presença de argumentos 
alusivos ao nacionalismo e (ii) averiguar a possível presença do folclore na educação escolar.

Relacionado à categoria $\mathrm{DE}$, encontrou-se, nos exemplares de $O$ Estado de São Paulo, um fragmento, relacionado com a emissão, pelo então Presidente da República Jânio Quadros, do Decreto no 51.215, em 21 de Agosto de 1961.

Relacionados à categoria FVE, não se encontrou nenhum fragmento.

O conteúdo encontrado nos exemplares de O Estado de São Paulo relacionado à categoria FE foi publicado nas datas: 21 e 23 de Agosto de 1955, 22 de Agosto dos anos 1957, 1959 e 1960, e 21 de Agosto do ano 1960. Relacionado à mesma categoria, encontrou-se conteúdo no Correio Popular, exemplar, de 09 de Julho de 1957.

A partir dos jornais e da legislação, ambos da época, folclore compreende: ( $i$ ) um patrimônio cultural brasileiro, (ii) algo do passado que se repete no presente e que não se renova, (iii) um aglomerado de culturas, ou seja, possui como característica ser múltiplo.

Portanto, uma definição que possivelmente contempla o conteúdo encontrado nos documentos citados compreenderia o folclore como um aglomerado de culturas, de origem temporal e caráter difusos, transmitido de uma geração a outra praticamente sem alterações em seu conteúdo através da educação, e que faz parte do patrimônio cultural nacional e da identidade do brasileiro.

\section{Conclusão}

A partir da discussão realizada acerca do significado de folclore, da análise dos fragmentos de jornal coletados e da legislação pertinente da época pode-se afirmar que existiu, sim, em Juscelino Kubitschek um plano de nação, parcialmente concretizado, que contou com a colaboração do folclore como elemento cultural na construção de uma suposta identidade coletiva nacional, ainda que múltipla. 
Constatou-se também a partir deste trabalho, que a relação entre educação e folclore se concretizou, entre outras medidas, na unificação curricular de uma determinada área do conhecimento diretamente relacionada ao folclore: o ensino de música. Essa mudança em âmbito nacional do currículo escolar aliada às manifestações folclóricas incentivadas pelo Governo em espaços não-escolares colaborou na construção de uma identidade coletiva nacional, ao mesmo tempo em que proporcionou uma compreensão das diferenças culturais presentes no país. O resultado desse encontro é o surgimento de uma relação dialógica entre as ideologias presentes no âmbito da instituição escola e as ideologias circundantes fora desta.

Uma das possíveis contribuições da discussão acerca a relação educação-folclore para a sociedade contemporânea é justamente a indagação o que é folclore e qual o seu significado para as relações sociais?

A segunda possível contribuição está em considerar a existência de no mínimo duas relações entre folclore e educação: a primeira é que o folclore, em si, é educativo; a segunda relaciona-se à presença do folclore como prática curricular real nas instituições escolares (sejam as "festas juninas" comumente realizadas nas instituições escolares, ou as atividades pedagógicas concernentes à celebração do "Dia do Folclore").

Pergunta-se, então: seria possível afirmar que, mesmo décadas depois do contexto estudado/pesquisado, as manifestações folclóricas (contemporâneas) traduzem ainda um aglomerado de culturas, de origem temporal e caráter difusos, transmitido de uma geração a outra praticamente sem alterações em seu conteúdo, e que faz parte do patrimônio cultural nacional e da identidade do brasileiro?

Se a resposta vier a ratificar essa hipótese, isso demonstra que é preciso cautela no que se refere a manifestações populares.

Folclore e cultura popular não possuem o mesmo significado.

A cultura popular não é integralmente estática, tampouco se traduz absolutamente em algo do ridículo ou de um passado longínquo e/ou desconhecido que foi congelado no tempo. O conceito cultura popular 
amplo, e deve ser compreendido e tido como o de cultura viva do povo, que acontece, que é, que tem força e, principalmente, tem significado para quem dela faz parte.

\section{Referências bibliográficas}

BIBLIOTECA EDUCAÇÃO E CULTURA. Carta do Folclore Brasileiro. Rio de Janeiro: MEC/FENAME, 1951.

CRUZ, Marta Vieira. Brasil nacional-desenvolvimentista (1946-1964). Disponível em:

http://www.histedbr.fae.unicamp.br/navegando/artigos frames/artigo 083.ht ml. Acesso em: 05 de Jun de 2009.

ENCINA, Ricardo de la; ONRAITA, Pérez de. Poder y Comunidad. In: Una sociología del nacionalismo. Pamplona: Pamiela, 2004.

FERNANDES, Florestan. Objeto e campo do folclore. In: FERNANDES, Florestan. O folclore em questão. 2. ed. São Paulo: Hucitec, 1989. Cap. 2, p. 23-27.

GRAMSCI, Antonio. Cadernos do cárcere: literatura. Folclore. Gramática. Volume 6. Trad. COUTINHO, Carlos Nelson et al. Rio de Janeiro: Civilização Brasileira, 2002. 495p.

GRUPPI, L. O conceito de hegemonia em Gramsci. 4.ed. Rio de Janeiro: Graal, 1978. Política. (Traduzido do original Il Concetto di egemonia in Gramsci por Carlos Nelson Coutinho)

LÖWY, Michael. Ideologias e Ciências Sociais: elementos para uma análise marxista. 16.ed. São Paulo: Cortez, 2003.

PORTELLI, Huges. Gramsci e a Questão Religiosa. Ed. Paulinas. São Paulo, 1984.

RIBEIRO, Maria Luisa Santos. Historia da educação brasileira: a organização escolar. São Paulo: Cortez, 1978.

ROMANELLI, Otaíza de Oliveira. A educação e o desenvolvimento brasileiro após 1930. In: História da Educação no Brasil. 14ed. Petrópolis: Vozes, 1992.

SAVIANI, Dermeval. As concepşões pedagógicas na bistória da educação brasileira. Disponível em: http://www.histedbr.fae.unicamp.br/navegando/artigos frames/artigo 036.ht ml. Acesso: 12 de Fev de 2009.

SCHLESENER, Anita Helena. Gestão democrática da educação: observações a partir de uma abordagem gramsciana. Disponível em: http://www.utp.br/proppe/X\%20seminario pesquisa/menu.htm. Acesso em: 23 de Abr de 2009. 
SILVA, Francisco de Assis. Educação brasileira no periodo do nacionaldesenvolvimentismo (TCC). Universidade Estadual de Campinas - Faculdade de Educação, 2008.

VIANA, Cibilis da Rocha. Reformas de base e a politica nacionalista de desenvolvimento: de Getúlio a Jango. Rio de Janeiro: Civilização Brasileira, 1980. (Retratos do Brasil). 